\title{
O ENSINO DE PORTUGUÊS COMO LÍNGUA NÃO-MATERNA: UMA EXPERIÊNCIA DE ENSINO-APRENDIZAGEM E ACOLHIMENTO
}

\author{
ENSEÑAR PORTUGUÉS COMO LENGUA NO MATERNA: UNA EXPERIENCIA DE \\ ENSEÑANZA-APRENDIZAJE Y ACOGIMIENTO
}

\author{
TEACHING PORTUGUESE AS A NON- NATIVE LANGUAGE: AN EXPERIENCE OF \\ TEACHING-LEARNING AND HOST
}

\author{
Karin Adriane Henschel Pobbe RAMOS ${ }^{1}$ \\ Eric Santos do NASCIMENTO2
}

RESUMO: O presente artigo tem como objetivo relatar uma experiência de ensino de Português como Língua Adicional (PLA) para o acolhimento de uma família de líbios e de argelinos que, atualmente, vive na cidade de Marília, no interior do estado de São Paulo. O processo descrito vem sendo desenvolvido como parte de uma pesquisa de iniciação científica, com bolsa do Conselho Nacional de Desenvolvimento Científico e Tecnológico $(\mathrm{CNPq})$, de um estudante do curso de licenciatura em Letras de uma universidade pública situada no interior do estado de São Paulo. O aporte teórico fundamenta-se em uma abordagem intercultural para o ensino de línguas. As considerações finais apontam para a necessidade de se compartilhar essas experiências para o fortalecimento da área do Português como Língua Não-Materna (PLNM).

PALAVRAS-CHAVE: Português Língua Não-Materna. Acolhimento. Relato de experiência.

RESUMEN: Este artículo tiene como objetivo relatar una experiencia de enseñanza de Portugués como Lengua Adicional (PLA) para acoger a una familia de libios y argelinos que actualmente vive en la ciudad de Marilia, en el interior del estado de São Paulo. El proceso descrito ha sido desarrollado como parte de una investigación de iniciación científica, con una beca del Conselho Nacional de Desenvolvimento Científico e Tecnológico (CNPq), de un estudiante de la carrera de Letras de una universidad pública ubicada en el interior del estado de São Paulo. La contribución teórica se basa en un enfoque intercultural de la enseñanza de idiomas. Las consideraciones finales apuntan a la necesidad de compartir estas experiencias para fortalecer el área del Portugués como Lengua No-materna (PLNM).

PALABRAS CLAVE: Portugués como Lengua No-materna. Acogimiento. Reporte de experiencia.

\footnotetext{
1 Universidade Estadual Paulista (UNESP), Assis - SP - Brasil. Docente do Departamento de Estudos Linguísticos, Literários e da Educação. ORCID: https://orcid.org/0000-0002-9850-1393. E-mail: karin.ramos@unesp.br

2 Universidade Estadual Paulista (UNESP), Assis - SP - Brasil. Discente do curso de Letras. ORCID: https://orcid.org/0000-0001-6046-9431.E-mail: eric.santos@unesp.br
} 
ABSTRACT: This paper aims to report an experience of teaching Portuguese as an additional language to host a family of Libyans and Algerians who currently live in the city of Marilia, in the countryside of the State of São Paulo. The described process has been developed as part of a scientific initiation research, with a grant from the National Council for Scientific and Technological Development (CNPq), by a student of Languages at a public university located in the countryside of the State of São Paulo. The theoretical contribution is based on an intercultural approach to language teaching. The final considerations point to the need to share these experiences to strengthen the area of Portuguese as a Non-Native Language.

KEYWORDS: Portuguese Non-Native Language. Host. Experience report.

\section{Introdução}

O presente artigo tem como objetivo relatar uma experiência de ensino de Português como Língua Adicional (PLA) ${ }^{3}$ para o acolhimento para uma família de líbios e de argelinos que, atualmente, vive na cidade de Marília, no interior do estado de São Paulo. O processo descrito vem sendo desenvolvido como parte de uma pesquisa de iniciação científica, com bolsa do Conselho Nacional de Desenvolvimento Científico e Tecnológico (CNPq), ${ }^{4}$ de um estudante do curso de licenciatura em Letras da Faculdade de Ciências e Letras de Assis da Universidade Estadual Paulista (UNESP).

A crescente diminuição das fronteiras - não sob o ponto de vista geográfico, mas social, econômico e político - entre diferentes países e as diferentes culturas que neles emergem, insere seus povos numa situação que, muitas das vezes, é de choque. E esse choque, antes mesmo de ser cultural, é linguístico, eis que também suas diferentes línguas passam a se relacionar de forma mais próxima, havendo a necessidade, nesse sentido, de se conhecer e, quase como consequência, de se aprender a língua do outro para que essa e tantas outras relações (em âmbito social, cultural, político, etc.) possam vir a se efetivar sem conflitos e incompreensões. É nesse momento que surge a necessidade de se (re)pensar metodologias e abordagens para o desenvolvimento do ensino de línguas não-maternas, com vistas a se possibilitar não só a comunicação, mas, também, a compreensão do mundo do

\footnotetext{
${ }^{3}$ Optou-se por referir como PLA o processo de ensino-aprendizagem que tem sido desenvolvido com essa família, pois, conforme lição de Schlatter e Garcez (2009, p. 127), trata-se da configuração de um acréscimo/adição de uma outra língua para todos eles, não se deixando de se considerar, assim, a presença de sua língua materna nesse processo, o árabe, e a segunda língua na qual a maior parte deles possui certa fluência, o inglês. Com isso, evita-se a ocorrência de um possível silenciamento desses sujeitos (ANUNCIAÇÃO, 2018), ao buscar se contribuir para o seu acolhimento no Brasil.

${ }^{4}$ Edital do Programa de Bolsa de Iniciação Científica (PIBIC) da UNESP.
} 
outro, da cultura e dos demais constituintes daquele(s) indivíduo(s) diversificado(s) e dos contextos em que eles estão inseridos, com que se passa a se relacionar.

Denota-se que vários são os motivos e diferentes as razões que inserem determinado(s) indivíduo(s) em contextos de manifestação cultural e linguística diferentes dos daqueles de seu cerne, sendo dos mais costumeiros a migração, ${ }^{5}$ que, muitas das vezes, acaba se fazendo forçosamente, em busca de refúgio em outros países, devido a conflitos políticos e outros que disso resultam, como conflitos armados e a guerra, em seu país de origem. Com isso, ao se desenvolver o ensino de línguas não-maternas a esses "novos falantes" - com enfoque aqui para o Português como Língua Não-Materna (PLNM) -, é importante levar-se em consideração que a aprendizagem da língua do outro não contribui apenas para a efetivação do diálogo, da comunicação entre esse(s) indivíduo(s) diverso(s) em sua(s) particularidade(s), mas também, no caso da migração - ainda mais em uma de situação de refugiado(s) -, para a possibilidade de se conceder um adequado acolhimento daqueles que vêm a apreender uma língua não-materna, para a melhora de sua qualidade de vida, que se reinicia em um outro país.

\section{Objetivo}

Buscar-se-á relatar as experiências que têm se constituído como resultado de uma pesquisa de iniciação científica que tem como foco os processos de ensino e de aprendizagem de PLNM, desenvolvido a partir de uma parceria entre o Centro de Línguas e Desenvolvimento de Professores $(\mathrm{CLDP})^{6}$ da Faculdade de Ciências e Letras de Assis/UNESP e a Diretoria de Ensino da Região de Marília, Estado de São Paulo.

Nesta pesquisa/projeto de extensão, tem-se ministrado, por meio da plataforma do Google Meet, aulas remotas de PLA a fim de se contribuir para o acolhimento de uma família originária da Líbia e da Argélia, países ao Norte da África, composta pelo pai, M. (de 50 anos), pela mãe, B. (de 43 anos), e por seus cinco filhos, Y. (de 16 anos), S. (de 14 anos), S. (de 09 anos), S. (de 07 anos) e A. (de 05 anos), ${ }^{7}$ que migraram para o Brasil há aproximadamente 04 (quatro) meses e, desde então, buscam se integrar a essa nova realidade, de contextos cultural e linguístico diferentes dos seus, especialmente na cidade de Marília,

\footnotetext{
${ }^{5}$ Segundo levantamento do Migration Data Portal (2020), o número de migrantes ao redor de todo o mundo, ao longo do ano de 2020, atingiu a média de 280,6 milhões de pessoas.

${ }^{6}$ Ação extensionista da XXXXXXXX.

7 A fim de que seja preservada a privacidade dos membros dessa família, optou-se por se referir a eles utilizando-se apenas as iniciais de seus prenomes.
} 
onde passaram a residir desde a sua chegada ao Brasil e onde os filhos do casal M. e B. foram prontamente matriculados como alunos da rede estadual de ensino básico.

\section{Fundamentação teórica}

Como aporte teórico, o processo tem sido fundamentado em uma perspectiva intercultural para o ensino de línguas estrangeiras (KRAMSCH, 2011), buscando-se compreender as implicações que tangenciam a construção de um entrelugar de interlocução (MENDES, 2011). Conforme Kramsch (2011), enquanto a competência comunicativa caracteriza-se pela negociação de significados em contextos autênticos da língua em uso, a competência intercultural lida com a circulação de valores e identidades por meio das culturas frequentemente escondidas atrás de uma ilusão de comunicação eficaz.

Toma-se como base, portanto, uma visão intercultural do processo de ensino e aprendizagem de línguas, na qual, nos eventos de ensino-aprendizagem, os sujeitos envolvidos constroem modos diferenciados de relacionar-se com a língua que ensinam e que aprendem, mais ou menos estrangeira, mais ou menos familiar ou próxima (MENDES, 2011, p. 139).

Ademais, o processo também tem se pautado na busca pelo desenvolvimento de uma "relação bidirecional” (GROSSO, 2021, p. 71) com M. e sua família, por meio da qual "[...] ensinante e aprendente cooperam e aprendem juntos, ultrapassam as questões do quotidiano, integram-se pelo bem-estar, pela confiança" (GROSSO, 2021, p. 71), buscando-se, com isso, possibilitar, por meio do ensino-aprendizagem de PLA, o acolhimento que tem se feito necessário para M. e seus familiares desde que migraram da Líbia para o Brasil.

\section{Uma experiência de ensino-aprendizagem como forma de acolhimento}

\section{O primeiro contato}

O primeiro contato com M. e sua família se deu em 06 de maio de 2021, remotamente, por meio da plataforma do Google Meet, esperando-se que, não apenas se efetivasse a apresentação entre os, a partir de então, alunos e professor, mas também que fosse possível se observar e se identificar quais seriam suas reais condições após migrarem para o Brasil, bem como as necessidades que se têm surgido em seu novo cotidiano, nas interações nas quais 
passaram a se inserir e foram inseridos, ${ }^{8}$ para que, assim, as aulas pudessem ser planejadas e ministradas a fim de, conforme se fizesse possível e suas reais condições permitissem, se contribuir para que M. e sua família tivessem, em paralelo com a aprendizagem do português como sua língua não-materna - como uma língua adicional -, o acolhimento minimamente suficiente em sua nova morada, em solo brasileiro.

Nesse momento, M. se encontrava com sua esposa B. e seus filhos mais velhos, Y. e S., na escola em que estão matriculados na cidade de Marília. Logo de início, se observou que ainda possuíam dificuldades para a oralização de sentenças mais extensas em português e na pronúncia de determinados fonemas, sendo que, em seguida, foi possível constatar que isso decorria do fato de confundirem tais fonemas com os que seriam, em tese, "equivalentes" na língua inglesa (seja vogais ou algumas consoantes), na qual possuem maior fluência, pois, segundo informado por eles posteriormente, se trata da segunda língua oficial adotada na Líbia, após o árabe.

No caso dos filhos menores de M. e B., as meninas S. e S. e o menino A., o contato se deu apenas após a primeira aula ministrada, o que em seguida se relatará.

\section{As diferentes demandas}

Diante da diferença etária existente entre os entes da família de M., foi-se necessário efetuar a divisão deles em dois grupos de alunos, em razão das demandas diversas que essa diferença etária imporia durante as aulas, cujo enfoque e objetivos, além das abordagens e métodos de ensino, não seria possível serem os mesmos. Ou seja, não seria viável agrupá-los todos numa única aula, pois isso prejudicaria não só o andamento das aulas, mas também sua aprendizagem do português, o que não seria o resultado almejado nem por eles, nem por nós.

Assim, os grupos ficaram divididos entre: os mais velhos, incluindo o próprio M. (de 50 anos), sua esposa B. (de 43 anos), seu filho mais velho, Y. (de 16 anos), e a filha mais velha, S. (de 14 anos); e os mais novos, sendo as filhas S. (de 09 anos) e S. (de 07 anos) e o filho mais novo A. (de 05 anos).

Tal divisão foi importante, pois se observou que os mais novos necessitavam de aulas cujo objetivo se centralizasse no desenvolvimento de seu letramento e alfabetização em português, sendo que, no caso de S. (de 07 anos) e do filho mais novo A. (de 05 anos), ainda estavam em processo de alfabetização em árabe, na Líbia, antes de migrarem para o Brasil

${ }^{8}$ Nesse momento, buscou-se efetuar o procedimento de análise, conforme destacado por Leffa (2016, p. 105106), visando o desenvolvimento das etapas seguintes, que partiriam do planejamento das aulas e da produção de materiais em acordo com as necessidades apresentadas por M. e seus familiares. 
com seus pais e irmãos, e, no caso de S. (de 09 anos), ainda que já estivesse em um nível mais avançado de alfabetização em sua língua materna, o árabe, constatou-se que seria necessário o desenvolvimento de sua compreensão de elementos básicos do português, sob a ótica do letramento e alfabetização, o que poderia ser efetivado nas aulas em conjunto com seus dois irmãos mais novos.

No caso dos demais, os pais M. e B. e os filhos mais velhos Y e S., a sua demanda se observou ser o desenvolvimento de sua produção oral e escrita em português, alinhada, é claro, com o desenvolvimento de sua leitura e escuta dessa língua não-materna. Pelo fato de possuírem certa fluência em inglês, denota-se que sua aprendizagem do PLA tem decorrido de maneira menos complexa e árdua como poderia se constituir, por exemplo, no caso de serem apenas falantes de árabe - língua bem mais "distante" do português do que o inglês, em termos de oralidade e escrita.

\section{O material didático}

Embora a situação de migração de $\mathrm{M}$. e sua família não se caracterize como de refúgio, ${ }^{9}$ observou-se que materiais didáticos elaborados para tal situação também poderiam auxiliar no planejamento das aulas a serem ministradas a eles, tendo em vista que um dos objetivos almejados seria o de possibilitar o seu acolhimento no Brasil, por meio da aprendizagem da PLA.

Dentre os materiais que têm servido como suporte para as aulas, destacamos:

- Pode Entrar: português do Brasil para refugiadas e refugiados, disponibilizado pela Agência da ONU para Refugiados (ACNUR);

- Portas Abertas: português para imigrantes: caderno básico e intermediário, disponibilizado pela Coordenadoria Pedagógica da Secretaria Municipal de Educação da cidade de São Paulo/SP;

- O português para falantes de outras línguas: o utilizador independente no país de acolhimento, disponibilizado pela Direção-Geral da Educação de Portugal;

- Brasil intercultural: língua e cultura brasileira para estrangeiros: ciclo básico - níveis 1 e 2, organizado por Edleise Mendes.

- Brasil intercultural: língua e cultura brasileira para estrangeiros: livro de exercícios: ciclo básico - níveis 1 e 2, organizado por Edleise Mendes.

Nesse ponto, é importante esclarecer que não se busca, ao ter tais materiais didáticos como suporte para as aulas que têm sido ministradas para M. e sua família, nos tornar apenas "simples administradoras do livro escolhido" (BRASIL, 2006, p. 40). Diante da situação de

${ }^{9}$ Por exemplo, M. ainda continua trabalhando em seu antigo emprego na Líbia. O que, segundo informou, tem feito por meio remoto. 
migração desses alunos, os conteúdos abordados nos materiais didáticos destacados têm auxiliado no planejamento das aulas, as quais, aquém de se pautar no que os autores desses materiais "considerou como mais adequado" (BRASIL, 2006, p. 40), têm se voltado às reais condições e necessidades apresentadas por M. e seus familiares desde sua vinda para o Brasil.

\section{As aulas como forma de acolhimento}

Até o momento de elaboração do presente relato, foram ministradas 13 aulas para os dois distintos grupos em que ficaram divididos M. e seus familiares. As aulas têm se dado semanalmente, às sextas-feiras, ocorrendo, primeiro, as aulas do grupo dos filhos menores de M. e B., S., S. e A.; e, em sequência, as aulas ministradas para M. e B. e seus dois filhos mais velhos, Y.e S.

Nas aulas ministradas para S., S. e A., diante da necessidade que possuem de desenvolvimento do seu letramento e alfabetização no português, sendo que ainda estava em curso tal processo mesmo em sua língua materna, o árabe, antes de migrarem para o Brasil, tem-se buscado o planejamento de aulas e atividades que possam, além de promover sua aprendizagem do PLA, contribuir, principalmente, para sua inserção no contexto de ensino vivenciado nas escolas brasileiras, com o qual têm-se deparado desde de sua vinda ao Brasil, sendo que foram todos matriculados no ensino básico brasileiro, especificamente na cidade de Marília, pouco depois de terem migrado da Líbia com seus pais e irmãos mais velhos.

É importante destacar que M. e sua família migraram para o Brasil já durante a pandemia da COVID-19 que, dentre tantos outros setores da sociedade, tem impactado, de formas que ainda não são possíveis de serem mensuradas, a continuidade e a regularidade da educação em solo brasileiro e em muitos outros países. Portanto, os filhos de M. e B. iniciaram seu percurso no ensino básico brasileiro tendo aulas remotas, o que inviabilizou, por exemplo, sua imersão no português, que seria possível em caso de terem aulas presenciais, pelo contato direto com a língua em seu uso, seja em razão de seus professores brasileiros e, além disso, dos colegas de escola, também brasileiros, com quem teriam convívio diário.

O mesmo se observa em relação aos filhos mais velhos de M. e B., Y. e S. Denota-se que Y., por ser mais fluente em inglês do que sua irmã S., vem enfrentando menos dificuldades para a aprendizagem durante as aulas de PLA. S., entretanto, necessita de tradução em alguns momentos para sua compreensão dos conteúdos ministrados, na maior parte das vezes para o árabe, o que é feito pelos pais ou pelo irmão Y. 
Nesse ponto também é importante destacar que, quanto aos filhos mais novos S., S. e A., durante as aulas eles têm sido acompanhados ou pelos pais M. e B., ou pelos irmãos mais velhos, Y. e S. Assim, em momentos de incompreensão dos conteúdos que vêm sendo apresentados durante as aulas, aqueles que os acompanham buscam traduzir para o árabe a explicação, a fim de que possam compreender o significado de determinadas palavras, expressões e outros mais elementos da língua portuguesa.

Por sua vez, nas aulas ministradas a M. e B. e aos seus dois filhos mais velhos, Y. e S., tem-se buscado o planejamento de conteúdos que possibilitem a aprendizagem de aspectos comunicativos do português, a fim de proporcionar sua autonomia no uso dessa língua nãomaterna nas diferentes situações que têm surgido desde sua vinda ao Brasil, bem como aspectos culturais, tendo em vista que migraram de um país com significativas diferenças em termos de socialização e de manifestações culturais em relação ao Brasil, a Líbia. Todos eles são muçulmanos, o que certamente os insere num contexto bem mais diversificado e, em determinados pontos, oposto ao que anteriormente encontravam na Líbia.

Apesar disso, durante as aulas todos eles têm-se mostrado bastante abertos à aprendizagem da língua portuguesa - eis que, segundo externaram, pretendem estabelecer residência no Brasil por um longo período -, sendo sempre participativos nas atividades propostas durante as aulas e naquelas propostas de forma complementar. Durante as aulas, levantam muitas questões sobre os conteúdos que lhes são apresentados e, diante da relação que já conseguimos estabelecer durante esse tempo, conversam sobre assuntos não só relacionados aos conteúdos abordados nas aulas, mas, também, sobre aqueles que surgem a partir disso.

Portanto, embora tenha havido a necessidade da divisão de M. e seus familiares em dois grupos de alunos, propondo-se conteúdos que objetivem suprir as demandas que a diferença etária entre eles tem feito emergir nesse momento, de maneira geral, tem-se buscado proporcionar, para além de sua aprendizagem do PLA, o acolhimento de todos eles a esse novo cotidiano que têm vivenciado após migrarem para o Brasil.

Conforme se foi possível constatar até o momento, pelo que M. e seus familiares vêm expressando, eles compreendem que as aulas ministradas contribuem para sua melhor integração nesse novo contexto, nesse novo país e morada, sendo, por exemplo, pedido por M. e B. que as aulas dadas aos seus filhos mais novos S., S. e A. continuassem mesmo após o retorno das aulas presenciais na escola em que estão matriculados, na cidade de Marília, o que ocorreu no início do mês de agosto de 2021. Assim, buscando-se proporcionar o seu 
acolhimento, mantiveram-se as aulas de PLA a eles às sextas-feiras, mas durante a manhã, pois suas aulas na escola se dão no período da tarde.

\section{Considerações finais}

A experiência compartilhada neste relato possibilita evidenciar, ainda que brevemente, a dimensão do quanto há por fazer neste campo do PLNM, sobretudo na sua especificidade do PLA e PLAc. Os recentes eventos mundiais - tais como os fenômenos migratórios de refugiados, as guerras emergentes, a ascensão de regimes autoritários, a pandemia da COVID19 e o retorno de movimentos extremistas que têm cada vez mais desconsiderado os direitos humanos -, são fatores que tornarão esse desafio ainda maior para os próximos anos.

Nesse sentido, compartilhar essas experiências pode contribuir para que se construa uma rede de pesquisas e de projetos que deem conta dessa demanda social.

AGRADECIMENTOS: Agradecimentos ao Conselho Nacional de Desenvolvimento Científico e Tecnológico (CNPq), pela bolsa do Programa Institucional de Bolsas de Iniciação Científica (PIBIC).

\section{REFERÊNCIAS}

ANUNCIAÇÃO, R. F. M. A língua que acolhe pode silenciar? Reflexões sobre o conceito de “português como língua de acolhimento". Revista X, Curitiba, PR. v. 13, n. 1, p. 35-56, 2018.

GROSSO, M. J.; TAVARES, A.; TAVARES, M. O português para falantes de outras línguas: o utilizador independente no país de acolhimento. 1. ed. Lisboa: Agência Nacional para a Qualificação, I.P., 2009.

GROSSO, M. J. Língua de acolhimento, língua de integração. Horizontes de Linguística Aplicada, v. 9, n. 2, p. 61-77, 2010.

KRAMSCH, C. The symbolic dimensions of the intercultural. Language and Teaching, $\mathrm{v}$. 44, n. 3, p. 354-367, 2011.

LEFFA, V. J. Língua estrangeira: ensino e aprendizagem. Pelotas: EDUCAT, 2016.

BRASIL. Ministério da Educação e Cultura. Trabalhando com a educação de jovens e adultos: avaliação e planejamento. Brasil, DF: MEC, 2006. Disponível em:

https://portal.mec.gov.br/secad/arquivos/pdf/eja_caderno4.pdf. Acesso em: 28 ago. 2021. 
MENDES, E. O português como língua de mediação cultural: por uma formação intercultural de professores e alunos de PLE. In: MENDES, E. (org.) Diálogos interculturais: ensino e formação em português língua estrangeira. Campinas, SP: Pontes, 2011.

MIGRATION PORTAL DATA. Total number of international migrants at mid-year 2020. Disponível em: https://www.migrationdataportal.org/internationaldata?i=stock_abs_\&t=2020. Acesso em: 28 ago. 2021.

SCHLATTER, M.; GARCEZ, P. Referenciais curriculares para o ensino de língua espanhola e língua inglesa. Porto Alegre: Secretaria de Educação do Estado, 2009. p. 127172.

\section{Como referenciar este artigo}

RAMOS, K. A. H. P.; NASCIMENTO, E. S. O ensino de português como língua nãomaterna: uma experiência de ensino-aprendizagem e acolhimento. Rev. EntreLínguas, Araraquara, v. 7, n. esp. 6, e021146, dez. 2021. e-ISSN: 2447-3529. DOI: https://doi.org/10.29051/el.v7iesp.6.15434

Submetido em: 30/08/2021

Revisões requeridas em: 14/10/2021

Aprovado em: 30/11/2021

Publicado em: 28/12/2021 